\title{
LXVIII. On the cause of the direction of continents and islands, peninsulas, mountain chains, strata, currents, winds, migrations and civilization
}

\section{Alexander Walker Esq.}

To cite this article: Alexander Walker Esq. (1833) LXVIII. On the cause of the direction of continents and islands, peninsulas, mountain chains, strata, currents, winds, migrations and civilization , Philosophical Magazine Series 3, 3:18, 426-431, DOI: 10.1080/14786443308648222

To link to this article: http://dx.doi.org/10.1080/14786443308648222

曲 Published online: 01 Jun 2009.

Submit your article to this journal $[\pi$

Џ Article views: 2

View related articles $\sqsubset$ 
Journal of Science there was an error in the printing, which might cause a good deal of trouble to any persons who wished to prove upon their own observations the formula I have deduced for calculating the heights, \&c., of arches from their azimuthal extents and altitudes. In the one paper, for $p=$ $1+c g$, and in the other $p=1 e+g$, it should have been printed $p=1+e g$.

The reader will, I am sure, acquit me of being a party to tolerating any notion that the meteor seen in the N.N.W. part of the heavens, over a distance of country of 200 to 300 miles, can possibly be located in the region of the clouds, or that the epithet borealis, acknowledged to be appropriately applied to this aurora, can be with any propriety attached to any variety of aqueous clouds seen in our lower atmosphere.

LXVIII. On the Cause of the Direction of Continents and Islands, Peninsulas, Mountain Chains, Strata, Currents, Winds, Migrations and Civilization. By Alexander W ALKER, Esq.* SHALL first endeavour to show that all of these have
one general direction.

With regard to continents and islands, which, as indicating the course of lands generally, it is proper to consider in connexion, the general direction of America is, evidently and extensively, north and south, as regards both its continent and the groups of islands to the south of the Strait of Magalhaens. The Old World, if we take into view its continent alone, has its chief direction east and west; but when we add to the further peninsula of Asia, the Indian isles, Australia and New Zealand, and observe that that world is deeply indented by the Indian Ocean, the Persian Gulf, the Red Sea, \&c.,-that, in fact, Asia is thus separated to half its depth from Europe and Africa,-it is impossible not to see, even in these two divisions of that world, a prevailing tendency to the same direction, north and south. The positions of the Black Sea and the Caspian, and of the White Sea and the Gulf of Obe, tend further to the same effect.

With regard to peninsulas, it is truly remarkable how universally they have this direction. Scandinavia, Spain, Italy, Greece, Africa itself, Arabia, India, Malaya, Corea, Kamtchatka, Alaska, California, South America itself, Florida, Nova Scotia, Greenland, run from north to south ; and the pen-

- Communicated by the Author. 
insulas on the Arctic Sea, generally from south to north. Thus nearly all of them run north and south.

With regard to mountain chains, the primary mountains also run generally north and south, and the secondary mountains accompany them in the same direction. In America we observe an alpine chain extending from the stony mountains to the Andes and continuing to Cape Horn*. This immense chain inclines westward, in its middle and northern part; and the opposite chains of Asia imcline, on the contrary, eastward; but the tendency of these, like other great mountain chains, is evidently north and south. The Jablounoy and Stanovoy mountains, joined by those east of the Lena, and forming the first of these chains, traverse the east of Asiatic Russia from north to south. The Ural mountains, forming the second of these chains, and running similarly north and south, separate Asiatic from European Russia. These may be regarded as continued eastward, as the Stanovoy are westward, toward the Altaï mountains, whence descend the chains which traverse Mongolia, Thibet and Hindoostan to the very extremity of India. In these, the great mountain chains of Asia, there is much irregularity; but if we regard the whole as thus stretching from the Arctic to the Indian Ocean, their direction is evidently north and south; and that which is true of the whole, is of course true of the greater number of parts, in which the long courses north and south of the Jablonnoy and of the Stanovoy mountains, of those east of the Lena, of the Ural mountains, of the Belor Tagh and of the Soliman mountains, and of the Ghauts, are very remarkablef. In the remainder of the Old World there are no mountain chains so vast as these; but in Europe the Finnish and Norwegian mountains, those of Illyria, the Apennines, the Cevennes and the Vosges, and the British mountains, all run north and south; and in Africa the littoral chain of the Red Sea, and the Lupata chain, stretching apparently from Cape Guardafui to the Cape of Good Hope, have a similar direction.

Such being the prevailing direction of mountain chains, corresponding with that of continents and islands, and of peninsulas, namely, north and south, it is evident that their sides, aspects or faces are as generally turned either eastward or westward.

As, however, while this is the case, the strata which com-

* The Allegany and Brazilian mountains have similar directions.

$\uparrow$ The Syrian and Arabian mountains have similar directions. 
pose them are generally more or less inclined, it is also evident, that one of these faces is as generally higher than the other, and its descent is consequently more abrupt.

From a comparison of this kind as to mountains having eastern and western aspects, it appears that generally a gradual elevation takes place on the eastern side, and is continued until the strata are suddenly broken off, and terminate in precipices or abrupt descents on the west.

Thus, the eastern part of Britain is generally flat; its mountains rise towards the west; and their most rugged sides are their western or north-western ones. The Alpes of Norway are inclined toward the east, and present precipices to the west or north-west. Libanus has a gentle inclination toward the Euphrates, and is precipitons toward the Mediterranean. The Ghauts slope toward the east, and form rugged mountains toward the west.

The preceding facts as to continents and islands, peninsulas, mountain chains, and strata, have nearly all been stated by various writers, but never, perhaps, brought into connexion; and I am not aware that any one has assigned a cause for such remarkable coincidences.

On viewing these facts in connexion, it appeared to me, that the earth's rotation accounted for the last of these phænomena-the inclination of strata, and that doing this, it accounted for the whole, because any means calculated thus to raise or project these strata, is calculated to form mountain chains, peninsulas and continents, as the slightest reflection will show.

It appeared to me that a globe, rotating with velocity, would tend perpetually to displace backward, or in a direction contrary to its motion, all the masses which are somewhat loose upon its surface; and that thus the earth, rotating from west to east, would have its looser masses projected westward, precisely as are strata and mountain chains.

The tendency of the centrifugal force of a rotating globe upon any loose but imbedded mass, is to throw it outward or upward from the centre: but, in so far as the motion by which it is actuated is expended in throwing it upward, that motion is lost from the mass's tendency to pass forward with the general matter of the globe; the mass will therefore remain relatively behind, - it will also retard that which is behind it, -its posterior part will be raised,-it will continue to rise so long as it receives from other retarded matter a solid support, - it will acquire a certain degree of obliquity, - and it will remain in that degree of obliquity, when the retrocession 
and various accidents of other masses refuse it further support.

If an oblong and curved vessel, loaded with a soft solid and having a hard solid partially imbedded in the middle of its surface, be attached to the rim of a wheel and made to rotate with velocity, the tendency above described of the imbedded mass is such as speedily to cause a concavity in the portion of the soft solid which is before it, and a convexity in the portion which is behind it,-a retrocession and obliquity of the whole mass, - as a very simple experiment will show.

Now that which is true of a small mass of matter is true of a greater; and thus the earth's rotation, being the cause of the retrocession and obliquity of its strata, is the cause of its mountain chains, peninsulas and continents.

The same is evidently the cause of the great equatorial or tropical current of the ocean, by which, especially between the tropics, and to 30 degrees of latitude north and south, its waters are perpetually carried from east to west, in a direction contrary to that of the rotation of the globe; and it is not less the cause of the boreal and austral polar currents, which join the preceding*.

The same also is evidently the cause of the winds which blow perpetually from the east in the torrid zone, with a movement quite distinct from that of the equatorial current; and it is not less the cause of the polar winds, which join theset.

It remains for me only to apply that which now appears to be a general law, to the migrations and the civilization of mankind-to show that these, which we call moral and political acts, are fundamentally physical ones.

As to migration, the savage who launches his canoe or spreads his sail, is naturally carried with the current and the wind; and, generally speaking, this would necessarily be in the direction already described. Hence, in the very earliest ages, no portion of the globe could long remain uncolonized.

- Malte-Brun has a partial glimpse of this doctrine, limited, however, to these currents; but even as to them he misleads himself by a notion of a force of inertia retarding the polar currents in their progress to supply equatorial evaporation,-instead of seeing the peculiar manner in which the centrifugal force operates upon the whole mass of the waters, equatorial as well as polar, and that, instead of polar inertia causing equatorial retardation the whole relative retardation being caused by the globe's rotation, it must be greatest at the equator and least toward the poles - the very reverse of his supposition.

+ Respecting these, Malte-Brun, following others, makes precisely the same error, as described in the preceding note on the waters. 


\section{$430 \mathrm{Mr}$. A. Walker on the Direction of Continents, \&c.}

If he commit himself not to the ocean, still he either voluntarily seeks, or is driven by new colonists or invaders to the bigher lands of the west.

Hence all the traditions and histories of the ancient world are of colonies and knowledge from the east-from India to Egypt, from Egypt to Greece, from Greece to Italy-from the plains of the two former to the mountains of the two latter. Hence, in all ages, the plains of Scythia have sent forth their myriads of wild and strange aspect, and of a hundred languages, to seize upon the enfeebled kingdoms of the west. Hence the New World is now fast peopling from the Old. Hence in North America, the population is slowly crussing the Allegany mountains toward the Cordilleras of its Pacific. shore. Hence in South America, Mexico and Peru and Chili are more densely peopled, while Guiana and Brazil and Paraguay are [comparatively] deserts.

Nor are these migrations to western and higher lands unreasoned. The climate of mountains is almost universally more salubrious than that of plains, and (which to selfish man is, perhaps, more important,) power has naturally, in all ages, been dependent on the possession of mountain chains. These are the real reasons of the hitherto mysterious fact, that " $\mathrm{em}$ pire constantly verges to the quarter of the setting sun."

Of this tendency an able writer says: "America certainly offers very singular facts towards the support of this mystical doctrine, in which, though we have no faith, yet there is con-. siderable pleasure in tracing the analogy of events." Faith may be essential in religion; it is worthless in philosophy; and $I$ trust $I$ have rendered its exercise no longer necessary upon this subject.

As to civilization, mountaineers have more universally a manly, brave and noble character than the inhabitants of plains, who are generally more phlegmatic and indolent. And the cause of this is not obscure. It is Humboldt, if I mistake not, who observes that " those who attend to their feeings, when ascending mountains, acknowledge that they experience in elevated situations, a buoyancy of spirits, and an alertness of mind, far exceeding that which they usually possess in the plains." But this, though true, is not enough. Such regions present great variety of temperature, and cold rather predominates than heat. 'This excites man to all those resources and all those arts, excellence in which constitutes civilization.

In addition to these wide but rapid views, I have only to observe that the precise line which, so far as our brief annals tell, civilization has traced, is worthy of notice. Its course from India to Egypt, from Egypt to Greece, which sent it for 
a moment backward in the same course, from Greece to Italy, whither it was twice sent from the same quarter, and from Italy to both sides of the Rhine and to Britain,-is in that westerly or north-westerly direction which conforms to, and so far confirms the dependence of all these phænomena on, one general law-the cause I have assigned.

\section{Alexander Walker.}

LXIX. On the Theory of Resistances in Statics. By the Rev. H. Moseley, B.A., Professor of Natural Philosophy in King's College, London*.

IN a paper inserted in the Philosophical Magazine for October, I have given a demonstration of the following theorem: If there be a system of forces in equilibrium among which there enter the resistances of any number of fixed points, then are these resistances such that their sum is a MINIMUM; each being considered a function of the coordinates of its point of application, taken with a positive sign, and subjected to the conditions imposed by the equilibrium of the rohole. I have also pointed out the steps by which this principle may be applied to the actual determination of the amount and direction of the resistance upon each point of the system in terms of the other forces which compose it.

It is my object at present to give the actual solution of that particular but very important case, of the more general proposition, in which the forces and resistances of the system are all parallel to one another. The solution of this case is entirely free from that elaboration of analysis which besets the more general proposition.

Let the plane of $x y$ be taken perpendicular to the given parallel directions of the forces of the system.

Let the resistances of the system be $\mathrm{P}_{1}, \mathrm{P}_{2}, \mathrm{P}_{3}, \& \mathrm{c}$., and let the coordinates of the points where these directions intersect the plane of $x y$, be $x_{1} y_{1}, x_{2} y_{2}, x_{3} y_{3}$, \&c. Also let the sum of those forces of the system which are not resistances be $M$, and the sums of their moments about the axes of $y$ and $x$ respectively $\mathrm{N}_{1}$ and $\mathrm{N}_{2}$.

By the known conditions of equilibrium, therefore, we have

$$
\left.\begin{array}{l}
\Sigma \mathrm{P}+\mathrm{M}=0 \\
\Sigma \mathrm{P} x+\mathrm{N}_{1}=0 \\
\Sigma \mathrm{P} y+\mathrm{N}_{2}=0
\end{array}\right\} \ldots \ldots \ldots \ldots \ldots \ldots \ldots
$$

* Communicated by the Author. 